\title{
Dialysis-related carpal tunnel syndrome in the past 40 years
}

\author{
Masaki Hatano ${ }^{1}$ (D) Izuru Kitajima ${ }^{1} \cdot$ Seizo Yamamoto ${ }^{1} \cdot$ Masaki Nakamura $^{1} \cdot$ Kazuya Isawa $^{1} \cdot$ Tatsuya Suwabe $^{2,3}$. \\ Junichi Hoshino $^{2,3} \cdot$ Naoki Sawa $^{2,3} \cdot$ Yoshifumi Ubara ${ }^{2,3}$
}

Received: 12 June 2021 / Accepted: 10 August 2021 / Published online: 20 August 2021

(c) The Author(s) 2021

\begin{abstract}
Purpose and method Patients on hemodialysis develop carpal tunnel syndrome (CTS) due to an accumulation of dialysisrelated $\beta 2$ microglobulin $(\beta 2 \mathrm{~m})$ amyloid (DRA). In Japan, dialysis technology has progressed remarkably in the past 40 years and has increased the time until patients require surgery for CTS. However, unclear is whether the time from the start of hemodialysis to the first surgery for CTS is associated with $\beta 2 \mathrm{~m}$ clearance by the different hemodialysis techniques. Therefore, we retrospectively evaluated $\beta 2 \mathrm{~m}$ clearance, serum $\beta 2 \mathrm{~m}$ levels, and the change in the length of this period in patients across 4 periods according to the year that first surgery for CTS was performed: period 1, 1982-1989; period 2, 1990-1999; period 3, 2000-2009; and period 4, 2010-2019.

Result A total of 222 patients who met the selection criteria were included. Mean $\beta 2 \mathrm{~m}$ clearance was $-1.8 \pm 16.7 \%$ in period 1 , and improved to $65.4 \pm 8.6 \%$ in period 3. Accordingly, the serum $\beta 2 \mathrm{~m}$ value after hemodialysis decreased significantly. The time from the start of hemodialysis to the first surgery for CTS was $12.4 \pm 2.9$ years in period 1 but increased to $21.8 \pm$ 6.3 years in period 3 . In multivariable linear regression analysis, the significant factors contributing to $\beta 2 \mathrm{~m}$ clearance were periods 2,3 , and 4 . In particular, the relation between removal of $\beta 2 \mathrm{~m}$ and the extension of the dialysis vintage in period 1 and 2 was remarkable compared with periods 3 and 4.

Conclusion Our findings indicate that improvement of $\beta 2 \mathrm{~m}$ clearance via advances in dialysis technology might result in a significant extension in the time between starting HD and the first surgery for CTS.
\end{abstract}

Keywords Carpal tunnel syndrome $\cdot$ Long-term hemodialysis $\cdot \beta 2$ microglobulin $\cdot \beta 2$ microglobulin clearance $\cdot$ Dialysisrelated amyloidosis

$\begin{array}{ll}\text { Abbreviations } \\ \text { Alb } & \text { Albumin } \\ \text { CTS } & \text { Carpal tunnel syndrome } \\ \text { CI } & \text { Confidence interval } \\ \text { DRA } & \text { Dialysis-related amyloidosis } \\ \text { RDT } & \text { Regular dialysis therapy } \\ \text { TP } & \text { Total protein } \\ \beta 2 \mathrm{~m} & \beta 2 \text { Microglobulin }\end{array}$

Masaki Hatano

hm0523jp@yahoo.co.jp

Yoshifumi Ubara

ubara@toranomon.gr.jp

1 Department of Orthopaedic Surgery, Toranomon Hospital, 1-3-1, Takatsu, Kawasaki, Kanagawa 212-0015, Japan

2 Department of Nephrology, Toranomon Hospital, 1-3-1, Takatsu, Kawasaki, Kanagawa 212-0015, Japan

3 Okinaka Memorial Institute for Medical Research, Toranomon Hospital, Minato City, Tokyo, Japan

\section{Introduction}

Advances in hemodialysis (HD) techniques are extending the lives of patients with chronic renal failure [1]. In Japan, almost 20,000 patients are on HD for longer than 20 years [1,2]. Long-term HD is well known to increase the prevalence of complications. One of the most harmful complications of HD is dialysis-related amyloidosis (DRA), which is due to the deposition of $\beta 2$ microglobulin $(\beta 2 \mathrm{~m})$ and adversely affects activities of daily living and quality of life $[3,4]$. A common complication of DRA is carpal tunnel syndrome (CTS), in which amyloid deposits compress the median nerve [5]. In 1985, Gejyo et al. reported that $\beta 2 \mathrm{~m}$-amyloid deposition was found in operative specimens from patients undergoing CTS who had been on HD for 8-14 years [6]. Thereafter, with advances in HD technology, the time between starting HD and undergoing the first surgery for CTS increased. However, the reasons for this increase remain unclear [7]. Therefore, we divided patients who underwent CTS surgery in the past 40 years into 4 
groups of 10-year periods, depending on the year of surgery, and compared $\beta 2 \mathrm{~m}$ clearance, serum $\beta 2 \mathrm{~m}$ levels, and the change in the time from the start of HD to the first surgery for CTS between the 4 groups.

\section{Methods}

The main complications of dialysis amyloidosis are carpal tunnel syndrome, cervical spondylosis, spinal canal stenosis, trigger finger, bone cyst of the femoral neck, etc. We examined the records of operations for amyloid complications in the patients included in this study. The surgery for CTS was found to be the first surgery for amyloid complications. The relationship between carpal tunnel syndrome and dialysis amyloid was investigated as follows.

\section{Indication for surgery for CTS}

Surgery for CTS was indicated only if physical signs of median nerve dysfunction were present according to electrodiagnostic nerve conduction study criteria, i.e., a distal motor latency of more than $4.5 \mathrm{~m} / \mathrm{second}$ and a sensory latency of more than $3.5 \mathrm{~m} / \mathrm{second}$, in cases where surgery was requested because of classical symptoms of CTS, including numbness, tingling, and occasional pain in the hand.

\section{Patients}

In this retrospective, single-center cohort study, we examined records of all patients who received regular HD at Toranomon Hospital, Tokyo, Japan, and underwent the first surgery for CTS at the Department of Orthopedic Surgery, Toranomon Hospital, between December 1982 and December 2019.

Patients were assigned to one of the following 4 periods, depending on when their first CTS surgery was performed: period 1, 1982-1989; period 2, 1990-1999; period 3, 2000-2009; and period 4, 2010-2019.

The study was performed in accordance with the Declaration of Helsinki and its revisions and approved by the local research ethics board (approval number: 2127-B).

\section{Clinical and laboratory parameters}

The following clinical data were collected from the medical records, including laboratory data at the first surgery for CTS: age at start of HD; time (years) from the start of HD until surgery for CTS; sex; primary disease responsible for end-stage renal failure requiring $\mathrm{HD} ; \beta 2 \mathrm{~m}$ clearance; and serum $\beta 2 \mathrm{~m}$, serum total protein, and serum albumin before and after HD. $\beta 2 \mathrm{~m}$ clearance, which indicates the removal efficiency of $\beta 2 \mathrm{~m}$ was evaluated with the following formula:
( $\beta 2 \mathrm{~m}$ value before dialysis $-\beta 2 \mathrm{~m}$ value after dialysis) / $\beta 2 \mathrm{~m}$ value before dialysis $\times 100$.

\section{History of the HD method (Fig. 1)}

Dialysis in Japan began in 1960, and by the year 2000, there had been major advances in dialysis technology, but the details of these advances have not been published in English paper, which can be found in Pub-Med service. Therefore, the history of dialysis was summarized as follows based on the documents left in our hospital and the books written in Japanese. In 1966, HD was introduced in our institute and was performed with a Kill dialyzer. This dialyzer was replaced in 1977 by a hollow fiber, low-flux dialyzer with a cellulose or cuprammonium cellulose membrane. A high-flux dialyzer with a high-performance membrane made of polysulfone, polymethylmethacrylate, or polyacrylonitrile was introduced in 1990; this dialyzer was better able to remove $\beta 2 \mathrm{~m}$, had better biocompatibility and caused lower complement activity. Because a large quantity of dialysate needed to pass through high-flux dialyzers, they required an ultrafiltration control system and a method to clean the dialysate. At first, an ion exchange resin and activated carbon were used to remove bacteria and chemical compounds from the dialysate. Subsequently, a reverse osmosis device was developed because the ion exchange resin used aluminum, and from about 1978 scientists became increasingly aware of the toxicity of aluminum. From about 2000, an endotoxin adsorption filter was used. This is the first time it has been used in Japan. At first, bicarbonate was used as the buffer for the dialysate. Acetate was introduced as the buffer in 1970, but bicarbonate was used again from 1974. The advances in dialyzer technology described above were accompanied after 1990 by marked improvements in the ability of HD to remove $\beta 2 \mathrm{~m}$.

There have been no major changes in hemodialysis technology since 2000, although on-line hemodiafiltration has been widely used in Japan since 2013 when it was covered by insurance.

\section{Statistical analyses}

Data were summarized as percentages or as the mean $\pm \mathrm{SD}$. Categorical variables were analyzed with the chi-square test, and continuous variables, with the Kruskal-Wallis $\mathrm{H}$ test. The surgery probability in the 4 groups was calculated with the Kaplan-Meier method. Cox proportional hazards models were used to estimate hazard ratios (HRs) and 95\% CIs for the association between the 4 groups and the period from the start of HD to the first surgery for CTS. Primary diseases causing HD were assigned to one of the following 3 groups: chronic glomerulonephritis, polycystic kidney, and other diseases. Multiple linear regression analysis was performed to evaluate the factors contributing to $\beta 2 \mathrm{~m}$ clearance 
Fig. 1 History of the dialysis method

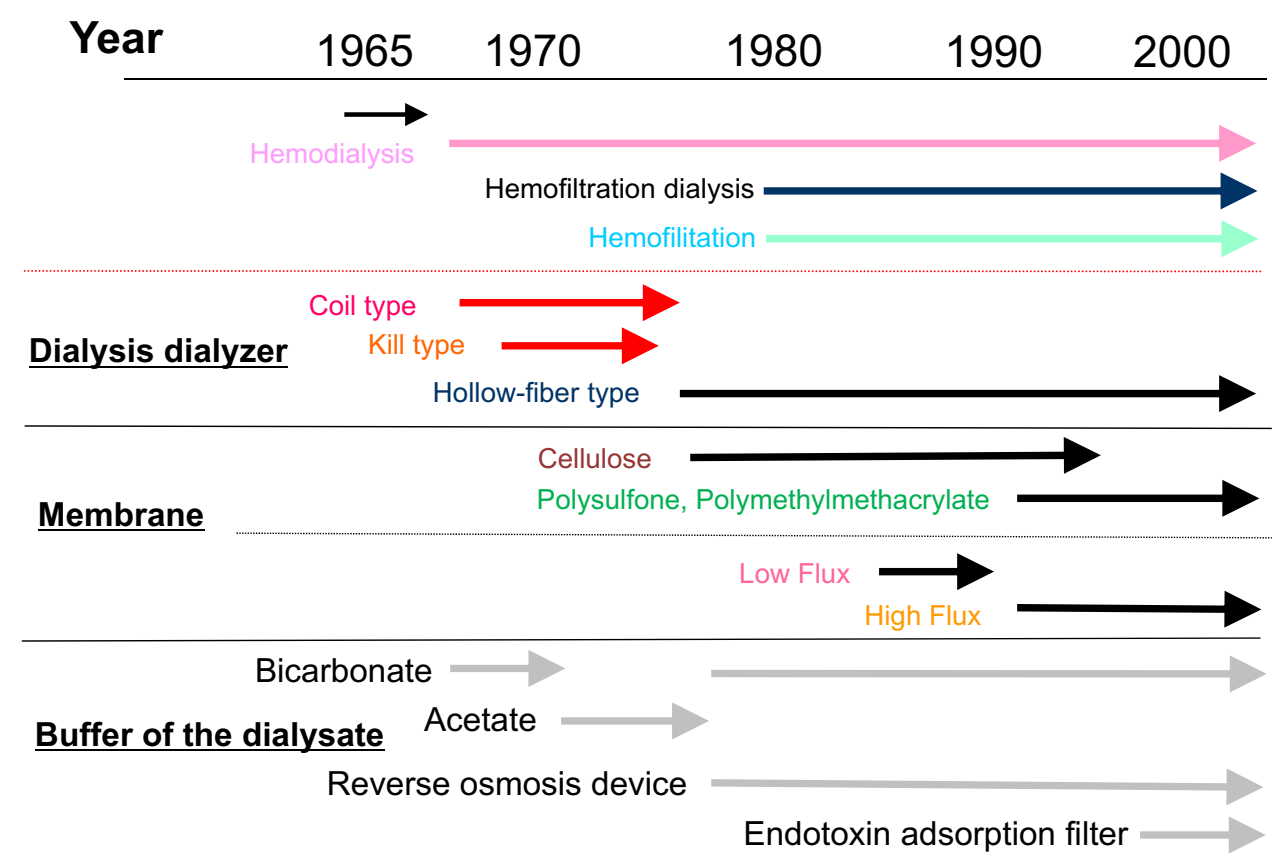

among selected demographic, biochemical, and clinical variables. Then, multiple linear regression analysis of the factors was carried out to identify those factors that were independently associated with $\beta 2 \mathrm{~m}$ clearance and serum $\beta 2 \mathrm{~m}$ levels after dialysis. The variance inflation factor (VIF) was used to check for multicollinearity in the model. All statistical analyses were performed with JMP PRO15 software. All p values were two-sided, and a $p$ value $<0.05$ was considered as indicative of statistical significance.

\section{Results}

A total of 239 patients received regular HD and underwent the first surgery for CTS between December 1982 and December 2019. We excluded 17 patients because of a history of peritoneal dialysis and kidney transplantation, repeated surgery for CTS, lack of clinical data, or negative staining of Congo red for $\beta 2 \mathrm{~m}$ in the surgical specimen. Therefore, 222 patients were eligible for inclusion in this study; $45.0 \%$ were men. The characteristics of patients are shown in Table 1.

In the 4 periods, mean $\beta 2 \mathrm{~m}$ clearance was as follows: period $1,-1.8 \pm 16.7 \%$; period $2,28.8 \pm 22.3 \%$; period 3 , $65.4 \pm 8.6 \%$; and period $4,68.6 \pm 3.9 \%$. Thus, $\beta 2 \mathrm{~m}$ clearance improved across the 4 periods. As a result, serum $\beta 2 \mathrm{~m}$ levels after dialysis decreased over the 4 periods, as follows: period 1, 43.2 $\pm 10.5 \mu \mathrm{g} / \mathrm{L}$; period $2,27.3 \pm 9.8 \mu \mathrm{g} / \mathrm{L}$; period $3,9.9 \pm 4.2 \mu \mathrm{g} / \mathrm{L}$; and period 4, $8.1 \pm 1.7 \mu \mathrm{g} / \mathrm{L}$. Patients were significantly younger at age at the first surgery for CTS in periods 1 and $2(57.4 \pm 11.7$ years and $56.7 \pm 9.2$ years, respectively) than in periods 3 and $4(63.1 \pm 8.1$ years and
$67.4 \pm 7.7$ years, respectively). The time from the start of HD until the first surgery for CTS increased across the 4 periods: period $1,12.4 \pm 2.9$ years; period $2,17.8 \pm 5.4$ years; period $3,21.8 \pm 6.3$ years; and period $4,22.4 \pm 6.7$ years.

Chronic glomerulonephritis was the most common primary disease responsible for end-stage renal failure, followed by polycystic kidney disease. Few patients had diabetes mellitus because they normally did not survive long enough to require surgery for CTS.

Kaplan-Meier curves for the time from the start of HD to the first surgery for CTS showed significant differences between the 4 groups ( $P<0.001, \log$-rank test) (Fig. 2).

In the adjusted analyses, the HR of time from the start of HD to the first surgery for CTS was lower in periods 2, 3, and 4 than in period 1 (Table 2; period 2 vs period 1: HR, 0.246 ; $95 \%$ CI $0.126-0.481$; period 3 vs period 1 : HR, 0.084; 95\% CI 0.043-0.164; period 4 vs period 1: HR, 0.048 ; 95\% CI 0.024-0.095). Age at start of HD was associated with the time between the start of HD and the first surgery for CTS (HR, 1.105; 95\% CI 1.087-1.124).

The factors contributing to $\beta 2 \mathrm{~m}$ clearance were evaluated by multivariable regression analysis (Table 3 ). Compared with period 1 , periods 2,3 , and 4 were significantly associated with increased $\beta 2 \mathrm{~m}$ clearance. The factors contributing to serum $\beta 2 \mathrm{~m}$ after HD were also evaluated by multivariable regression analysis (Table 3 ). Period 3 and 4 were significantly associated with decreased serum $\beta 2 \mathrm{~m}$ after dialysis and serum $\beta 2 \mathrm{~m}$ levels before HD were significantly associated with increased serum $\beta 2 \mathrm{~m}$ after HD. 
Table 1 Baseline characteristics of study population

\begin{tabular}{|c|c|c|c|c|c|c|}
\hline & All & $\begin{array}{l}\text { Period } 1 \\
1982-1989\end{array}$ & $\begin{array}{l}\text { Period } 2 \\
1990-1999\end{array}$ & $\begin{array}{l}\text { Period } 3 \\
2000-2009\end{array}$ & $\begin{array}{l}\text { Period } 4 \\
2010-2019\end{array}$ & $P$ \\
\hline Number of patients & 222 & 14 & 39 & 81 & 88 & \\
\hline $\operatorname{Man}(\%)$ & 45.0 & 42.3 & 43.6 & 48.1 & 43.2 & 0.9193 \\
\hline Age at start of hemodialysis (years) & $42.4 \pm 12.1$ & $45 \pm 13.6$ & $38.9 \pm 11.6$ & $41.0 \pm 12.1$ & $45.0 \pm 11.3$ & 0.0138 \\
\hline Age at the first surgery for CTS (years) & $63.3 \pm 9.3$ & $57.4 \pm 11.7$ & $56.7 \pm 9.2$ & $63.1 \pm 8.1$ & $67.4 \pm 7.7$ & $<0.0001$ \\
\hline Time from the start of hemodialysis (years) & $20.8 \pm 6.7$ & $12.4 \pm 2.9$ & $17.8 \pm 5.4$ & $21.8 \pm 6.3$ & $22.4 \pm 6.7$ & $<0.0001$ \\
\hline$\beta 2 \mathrm{M}$ clearance $(\%)$ & $49.6 \pm 28.2$ & $-1.8 \pm 16.7$ & $28.8 \pm 22.3$ & $65.4 \pm 8.6$ & $68.6 \pm 3.9$ & $<0.0001$ \\
\hline Serum $\beta 2 \mathrm{M}$ levels before dialysis $(\mu \mathrm{g} / \mathrm{L})$ & $31.7 \pm 9.2$ & $42.6 \pm 8.7$ & $38.0 \pm 5.6$ & $28.2 \pm 8.1$ & $25.9 \pm 3.9$ & $<0.0001$ \\
\hline Serum $\beta 2 \mathrm{M}$ levels after dialysis $(\mu \mathrm{g} / \mathrm{L})$ & $17.5 \pm 14.0$ & $43.2 \pm 10.5$ & $27.3 \pm 9.8$ & $9.9 \pm 4.2$ & $8.1 \pm 1.7$ & $<0.0001$ \\
\hline Total protain before dialysis $(\mathrm{g} / \mathrm{dL})$ & $6.7 \pm 0.6$ & $6.9 \pm 0.8$ & $7.0 \pm 0.3$ & $6.7 \pm 0.5$ & $6.4 \pm 0.6$ & 0.018 \\
\hline Total protain after dialysis $(\mathrm{g} / \mathrm{dL})$ & $7.3 \pm 0.9$ & $7.9 \pm 0.5$ & $7.3 \pm 0.5$ & $7.3 \pm 1.0$ & $6.9 \pm 0.7$ & 0.0254 \\
\hline Albumin before dialysis $(\mathrm{g} / \mathrm{dL})$ & $3.3 \pm 0.4$ & $3.4 \pm 0.5$ & $3.4 \pm 0.3$ & $3.2 \pm 0.3$ & $3.2 \pm 0.5$ & 0.0548 \\
\hline Albumin after dialysis (g/dL) & $3.4 \pm 0.5$ & $3.8 \pm 0.5$ & $3.4 \pm 0.3$ & $3.3 \pm 0.5$ & $3.3 \pm 0.6$ & 0.1219 \\
\hline \multicolumn{7}{|l|}{ Primary diasese reqiring hemodialysis } \\
\hline Chronic glomerulonephritis & 112 & 9 & 24 & 39 & 40 & \\
\hline Polycystic kidney disease & 32 & 2 & 5 & 14 & 11 & \\
\hline Nephropathy of pregnancy/pregnancy toxemia & 7 & 1 & 2 & 2 & 2 & \\
\hline Lupus nephritis & 6 & & & 3 & 3 & \\
\hline Nephrosclerosis & 4 & & 1 & & 3 & \\
\hline Diabetes & 3 & & 1 & & 2 & \\
\hline Gouty kidney & 3 & 1 & 1 & & 1 & \\
\hline Obstructive urinary tract desease & 3 & & & & 3 & \\
\hline Chronic pyelonephritis & 2 & & & 1 & 1 & \\
\hline Malignant hypertension & 2 & & & & 2 & \\
\hline Fanconi syndrome & 1 & & 1 & & & \\
\hline Acute glomerulonephritis & 1 & & & 1 & & \\
\hline Hypoplastic kidney & 1 & & & 1 & & \\
\hline Purpura nephritis & 1 & & & 1 & & \\
\hline Renal tuberculosis & 1 & & & 1 & & \\
\hline Amyloidosis & 1 & & & & 1 & \\
\hline Unknown & 42 & 1 & 4 & 18 & 19 & \\
\hline
\end{tabular}

Fig. 2 Kaplan-Meier estimates for the time from the start of hemodialysis to the first surgery for carpal tunnel syndrome by periods: period 1, 1982-1989; period 2, 1990-1999; period 3, 2000-2009; and period 4, 2010-2019 $(P<0.001$ in the log-rank comparison between the curves)
Kaplan-Meier curves for time from the start of hemodialysis to the first surgery for CTS

Period 4(2010-2019)

Period 3(2000-2009)

Period 2(1990-1999)

Period 1(1982-1989)

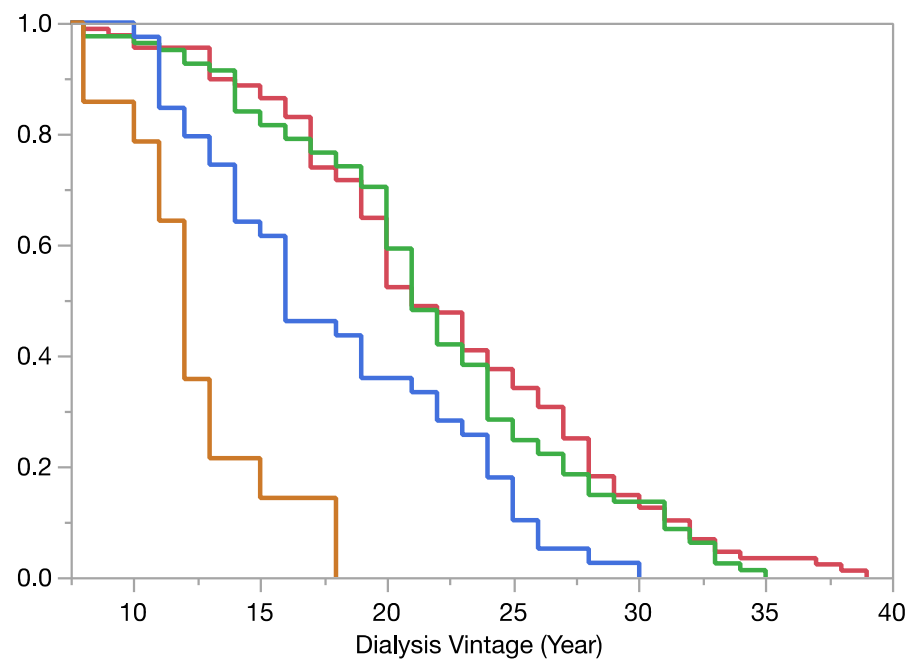


Table 2 Association with increased risk of longer time from the start of hemodialysis to the first surgery for carpal tunnel syndrome in each of the 4 periods

\begin{tabular}{llllll}
\hline Baseline factors & & $n$ & Hazard ratio & 95\% CI & $P$ \\
\hline Year & & & & & \\
& Period 1 (1982-1989) & 14 & & & \\
& Period 2 (1990-1999) & 39 & 0.246 & $0.126-0.481$ & $<.0001$ \\
& Period 3 (2000-2009) & 81 & 0.084 & $0.043-0.164$ & $<.0001$ \\
& Period 4 (2010-2019) & 88 & 0.048 & $0.024-0.095$ & $<.0001$ \\
Sex & Male & & & & \\
& Female & 100 & 1.044 & $0.798-1.366$ & 0.755 \\
Age at start of regular & & 122 & 0.958 & & \\
dialysis therapy (year) & & 222 & 1.105 & $1.087-1.124$ & $<.0001$ \\
Primary disease & & & & & \\
& Chronic glomerulonephritis & 112 & & & \\
& Polycystic kidney & 32 & 1.119 & $0.737-1.698$ & 0.599 \\
& Otherwise & 78 & 1.158 & $0.861-1.559$ & 0.322 \\
\hline
\end{tabular}

Table 3 Multivariable regression analysis for $\beta 2 \mathrm{~m}$ clearance and serum $\beta 2 \mathrm{~m}$ levels after dialysis

\begin{tabular}{|c|c|c|c|c|c|c|}
\hline Baseline factors & & Estimate & Lower $95 \%$ & Upper $95 \%$ & $\beta$ & $P$ \\
\hline \multicolumn{7}{|l|}{ Multivariable regression analysis for $\beta 2 M$ clearance } \\
\hline \multicolumn{7}{|l|}{ Year } \\
\hline & Period 2 & -8.189 & -14.525 & -1.853 & -0.174 & 0.0123 \\
\hline & Period 3 & 22.859 & 17.431 & 28.286 & 0.565 & $<.0001$ \\
\hline & Period 4 & 26.249 & 18.486 & 34.013 & 0.59 & $<.0001$ \\
\hline \multicolumn{7}{|l|}{ Sex } \\
\hline & Male & 0.977 & -2.316 & 4.27 & 0.034 & 0.554 \\
\hline \multicolumn{7}{|l|}{ Primary disease } \\
\hline & Chronic glomerulonephritis & 1.84 & -3.137 & 6.818 & 0.059 & 0.461 \\
\hline & Polycystic kidney & -0.674 & -8.144 & 6.796 & -0.014 & 0.857 \\
\hline Dialysis Vintage & & -0.046 & -0.812 & 0.721 & -0.12 & 0.905 \\
\hline Age at start of regular dialysis therapy (year) & & -0.359 & -0.755 & 0.037 & -0.157 & 0.07 \\
\hline Serum $\beta 2$ microglobulin levels before dialysis $(\mu \mathrm{g} / \mathrm{L})$ & & -0.248 & -0.723 & 0.227 & -0.083 & 0.299 \\
\hline Total protain before dialysis & & 2.471 & -3.592 & 8.533 & 1.289 & 0.417 \\
\hline \multicolumn{7}{|c|}{ Multivariable regression analysis for serum $\beta 2 M$ levels after dialysis } \\
\hline \multicolumn{7}{|c|}{ Year } \\
\hline & Period 2 & 1.659 & -0.97 & 4.289 & 0.07 & 0.211 \\
\hline & Period 3 & -8.881 & -11.134 & -6.628 & -0.436 & $<.0001$ \\
\hline & Period 4 & -9.302 & -12.524 & -6.079 & -0.415 & $<.0001$ \\
\hline \multicolumn{7}{|l|}{ Sex } \\
\hline & Male & -0.857 & -2.223 & 0.51 & -0.059 & 0.214 \\
\hline \multicolumn{7}{|l|}{ Primary disease } \\
\hline & Chronic glomerulonephritis & -0.045 & -2.11 & 2.021 & -0.003 & 0.966 \\
\hline & Polycystic kidney & -0.787 & -3.888 & 2.314 & -0.033 & 0.613 \\
\hline Age at start of hemodialysis (year) & & 0.176 & 0.012 & 0.34 & 0.153 & 0.036 \\
\hline Serum $\beta 2$ microglobulin levels before dialysis $(\mu \mathrm{g} / \mathrm{L})$ & & 0.606 & 0.408 & 0.803 & 0.401 & $<.0001$ \\
\hline Total protain before dialysis & & 0.082 & -2.435 & 2.598 & 0.003 & 0.948 \\
\hline
\end{tabular}




\section{Discussion}

In this study, we examined whether developments in HD techniques over the past 40 years improved $\beta 2 \mathrm{~m}$ clearance and serum $\beta 2 \mathrm{~m}$ levels and affected the time between starting HD and undergoing the first surgery for CTS. Indeed, we found that $\beta 2 \mathrm{~m}$ clearance improved from period 1 , the first 10 -year period, to period 4 and that serum $\beta 2 \mathrm{~m}$ levels also decreased. The time from the start of HD to the first surgery for CTS increased from period 1 to period 4.

Gejyo et al. extracted $\beta 2 \mathrm{~m}$ with a molecular weight of 11,000 Daltons from amyloid tissue of patients with CTS, and $\beta 2 \mathrm{~m}$-related amyloid subsequently became known as dialysis-related amyloidosis (DRA) [8]. Yamamoto et al. reported that age, duration of $\mathrm{HD}$, type of dialysis membrane used, chronic inflammation, advanced glycation, oxidation, and direct cell toxicity were also major risk factors for DRA [9]. Küchle et al. compared 10 patients treated with HD with low-flux cuprophane membranes with 10 patients treated with HD with high-flux polysulfone membranes; after 6 years, they found no clinical signs of DRA in patients dialyzed with high-flux polysulfone membranes but CTS or osteoarticular lesions or both in 8/10 of patients dialyzed with cuprophane low-flux HD membranes. Furthermore, serum levels of $\beta 2 \mathrm{~m}$ were significantly lower in patients dialyzed with high-flux polysulfone membranes [10].

Schwalbe et al. compared the prevalence of $\beta 2 \mathrm{~m}$ amyloidosis in 1988 and 1996 and found that high-flux synthetic dialysis membranes were used more frequently in 1996, as was reverse osmosis water plus bicarbonate buffer for dialysate preparation. Furthermore, the prevalence and severity of $\beta 2 \mathrm{~m}$ amyloidosis unexpectedly decreased from 1988 to 1996 [11].

Lornoy et al. reported that treatment with on-line hemodiafiltration with a highly permeable and biocompatible membrane is an efficient, well-tolerated, and safe technique that leads to a low prevalence of dialysis amyloidosis and a superior phosphate clearance [12].

Nakai et al. reported that in Japan the prevalence of CTS surgery decreased from $48.0 \%$ in a 1999 survey to $23.2 \%$ in a 2010 survey, and from $70.8 \%$ to $51.5 \%$ among patients with a dialysis vintage of 25 years or more [13]. In Poland, from 2005 to 2008 the duration of dialysis therapy in patients with CTS ranged from 4 to 30 years (mean, 16.05 years) [14]. In Germany, from 2009 to 2011 CTS due to amyloidosis was seen in as many as $22 \%$ of patients after 10 years of HD and in $50 \%$ of patients after 14 years of HD [15].

Hoshino et al. presented the results of a comparison of patients assessed in Japanese nationwide surveys in 1998 and 2010. The reduction of the time until the first surgery for CTS was most prominent in patients with a longer dialysis vintage, younger patients, and patients with lower pre-dialysis $\beta 2 \mathrm{~m}$ levels [16]. Hoshino et al. reported that the odds ratios of the first surgery for CTS doubled with every 5-year increase in dialysis vintage and were highest for patients aged 60-70 years [17]. Nishi et al. reported that CTS appeared significantly earlier than trigger finger. In the advanced phase of DRA, knee joint pain was a major cause of decreased activities of daily living in patients with clinical DRA [18].

In Table 1, we showed that the number of patients underwent CTS surgery increase from the period 1 to the period 4 . This is due to the fact that the number of dialysis patients in Japan has been increasing every 10 year; the number of patients in Japan who have been on dialysis for more than 10 years was 13,000 in 1985, 33,000 in 1995, 59,000 in 2005 and 89,000 in 2015 according to a survey by the Japanese Society for Dialysis Therapy Renal Data Registry Committee [19]. Hoshino et al. reported that the number of patients receiving the first surgery for CTS was 647 with dialysis vintage of $17.4 \pm 6.0$ years on 1998 cohort in Japan, and was 2157 with dialysis vintage of $18.2 \pm 9.5$ years for 2010 cohort [17].

In conclusion, dialysis technology in Japan has progressed remarkably in the past 40 years and has had a positive effect on the occurrence of CTS related to accumulation of DRA. $\beta 2 \mathrm{~m}$ clearance improved across the 4 decades and serum $\beta 2 \mathrm{~m}$ before and after HD consequently decreased. The time from the start of HD to the first surgery for CTS increased. In particular, the relation between removal of $\beta 2 \mathrm{~m}$ and the extension of the dialysis vintage in period 1 and 2 was remarkable compared with period 3 and 4 . From the above previous reports and our results, we believe that the better removal of $\beta 2 \mathrm{~m}$ via the advancement of dialysis technology might contribute to the extension of the dialysis vintage of patients undergoing surgery for CTS.

\section{Limitations}

The current study has several limitations. First, we used the first surgery for CTS as a proxy for advanced DRA, but information is needed on other complications of DRA, such as trigger finger and destructive spondyloarthritis. The surgery for CTS was found to be the first surgery for amyloid complications. The relationship between carpal tunnel syndrome and dialysis amyloid was investigated. Significant extension in the time between starting HD and the first surgery for CTS was explained by $\beta 2 \mathrm{~m}$ clearance alone. Second, the frequency of the primary disease requiring HD was different from that in the Japanese dialysis therapy renal data registry [1], where polycystic kidney is the most common primary disease among all patients receiving HD.

\section{Key learning points}

Long-term hemodialysis is well known to increase the prevalence of complications. A common complication of dialysisrelated amyloidosis (DRA) is carpal tunnel syndrome (CTS). 
However, there are few reports investigating incidence for DRA and a historical perspective of the historical characteristics of DRA have not been clarified.

This study aimed to clarify the historical perspective on the characteristics of DRA and the involvement of $\beta 2$ microglobulin according to the incidence of first-time carpal tunnel release surgery as proxy for DRA onset.

The time from the start of hemodialysis to the first surgery for CTS was $12.4 \pm 2.9$ years in $1980-1990$ but increased to $21.8 \pm 6.3$ years in $2000-2010$.

Our findings indicate that improvements in the efficiency of $\beta 2 \mathrm{~m}$ removal by hemodialysis decreased the accumulation of DRA and, thus, increased the time until patients require their first surgery for CTS.

Acknowledgements We thank Seiko Iyoda, Hiroyuki Ogawa, and Takeshi Shibata (clinical engineers, Toranomon Hospital) for providing valuable information on the history of dialysis techniques, Nobuhide Mimura, Hiroshi Mihei, Shigeko Hara, Yoshio Suzuki (founding members of nephrology), Yoshihisa Mikami, Shintaro Tachibana (founding orthopedic members), Mitsuru Hara (founding pathologist member) for valuable clinical contribution, and Nobuaki Michihata (Department of Clinical Epidemiology and Health Economics, School of Public Health, The University of Tokyo) and Yusuke Sasabuchi (Jichi Medical University Data Science Center Lecturer) for their valuable instruction in how to perform the statistical analysis.

\section{Declarations}

Conflict of interest The authors declare no competing financial interests and no conflicts of interest.

Statement of ethics The present report was produced in conformity with the Declaration of Helsinki, and the patients gave written informed consent for their data to be analyzed.

Open Access This article is licensed under a Creative Commons Attribution 4.0 International License, which permits use, sharing, adaptation, distribution and reproduction in any medium or format, as long as you give appropriate credit to the original author(s) and the source, provide a link to the Creative Commons licence, and indicate if changes were made. The images or other third party material in this article are included in the article's Creative Commons licence, unless indicated otherwise in a credit line to the material. If material is not included in the article's Creative Commons licence and your intended use is not permitted by statutory regulation or exceeds the permitted use, you will need to obtain permission directly from the copyright holder. To view a copy of this licence, visit http://creativecommons.org/licenses/by/4.0/.

\section{References}

1. Hanafusa N, Nakai S, Iseki K, et al. Japanese society for dialysis therapy renal data registry-a window through which we can view the details of Japanese dialysis population. Kidney Int Suppl. 2015;5(1):15-22.

2. Akizawa T. Current status of dialysis therapy and related clinical guidelines in Japan. JMAJ. 2010;53:185-7.

3. Suwabe T, Ubara Y, Inoue M, et al. What can we learn from a patient on dialysis for 42 years? Clin Nephrol. 2014;81(6):427-34.
4. Tagami A, Tomita M, Adachi S, et al. Epidemiological survey and risk factor analysis of dialysis-related amyloidosis including destructive spondyloarthropathy, dialysis amyloid arthropathy, and carpal tunnel syndrome. J Bone Miner Metab. 2020;38(1):78-85.

5. Scarpioni R, Ricardi M, Albertazzi V, et al. Dialysis-related amyloidosis: challenges and solutions. Int J Nephrol Renovasc Dis. 2016;9:319-28.

6. Gejyo F, Yamada T, Odani S, et al. A new form of amyloid protein associated with chronic hemodialysis was identified as beta 2-microglobulin. Biochem Biophys Res Commun. 1985;129(3):701-6.

7. Jadoul M, Garbar C, Noël H, et al. Histological prevalence of beta 2-microglobulin amyloidosis in hemodialysis: a prospective post-mortem study. Kidney Int. 1997;51(6):1928-32.

8. Gejyo F, Homma N, Suzuki Y, et al. Serum levels of beta 2 -microglobulin as a new form of amyloid protein in patients undergoing long-term hemodialysis. N Engl J Med. 1986;314(9):585-6.

9. Yamamoto S, Kazama JJ, Narita I, et al. Recent progress in understanding dialysis-related amyloidosis. Bone. 2009;45(Suppl 1):S39-42.

10. Küchle C, Fricke H, Held E, et al. High-flux hemodialysis postpones clinical manifestation of dialysis-related amyloidosis. Am J Nephrol. 1996;16(6):484-8.

11. Schwalbe S, Holzhauer M, Schaeffer J, et al. Beta 2-microglobulin associated amyloidosis: a vanishing complication of long-term hemodialysis? Kidney Int. 1997;52(4):1077-83.

12. Lornoy W, Becaus I, Billiouw JM, et al. On-line haemodiafiltration. Remarkable removal of beta2-microglobulin Long-term clinical observations. Nephrol Dial Transplant. 2000;15(1):49-54.

13. Nakai S, Iseki K, Itami N, et al. An overview of regular dialysis treatment in Japan (as of 31 December 2010). Ther Apher Dial. 2012;16(6):483-521.

14. Kopeć J, Gadek A, Drozdz M, et al. Carpal tunnel syndrome in hemodialysis patients as a dialysis-related amyloidosis manifestation-incidence, risk factors and results of surgical treatment. Med Sci Monit. 2011;17(9):CR505-9.

15. Schiffl H. Impact of advanced dialysis technology on the prevalence of dialysis-related amyloidosis in long-term maintenance dialysis patients. Hemodial Int. 2014;18(1):136-41.

16. Hoshino J, Yamagata K, Nishi S, et al. Significance of the decreased risk of dialysis-related amyloidosis now proven by results from Japanese nationwide surveys in 1998 and 2010. Nephrol Dial Transplant. 2016;31(4):595-602.

17. Hoshino J, Yamagata K, Nishi S, et al. Carpal tunnel surgery as proxy for dialysis-related amyloidosis: results from the Japanese society for dialysis therapy. Am J Nephrol. 2014;39:449-58.

18. Nishi S, Hoshino J, Yamamoto S, et al. A multicenter cross sectional study for bone-articular lesions associated with dialysis related amyloidosis in Japan. Nephrology (Carlton). 2018;23(7):640-5.

19. Nitta K, Goto S, Masakane I, Hanafusa N, Taniguchi M, Hasegawa T, Nakai S, Wada A, Hamano T, Hoshino J, Joki N, Abe M, Yamamoto K, Nakamoto H. The Japanese Society for Dialysis Therapy Renal Data Registry Committee. Annual dialysis data report for 2018, JSDT Renal Data Registry: survey methods, facility data, incidence, prevalence, and mortality. Renal Replacement Therapy, 2020

Publisher's Note Springer Nature remains neutral with regard to jurisdictional claims in published maps and institutional affiliations. 